\title{
Commentary: Is Collective Administration of Copyrights Justified by the Economic Literature? $^{1}$
}

\author{
Ariel Katz ${ }^{2}$
}

\section{A. INTRODUCTION}

A good starting point for any reasoned policy-oriented discussion of the merits of collective administration of copyright are that the following premises, in a liberal market-based economy, market competition is the rule, and, as a corollary, monopoly is the exception. Prices and other terms of trade are best determined by market players, not by government agencies. While accepting such premises does not preclude the possibility that in some situations fully competitive conditions will not function as well as expected - and intellectual property rights, properly designed, are an example of a solution to such situations - these premises imply two questions that need to be answered: First, what justifies replacing a system of competition between copyright owners with

1 Professor Jacques Robert presented a paper in which he argued that the economic literature on bundling of information goods provides a novel justification for the collective administration of copyrights and made a few other recommendations relating to collective administration of copyright. This comment critically examines this bundling argument as well as the other recommendations.

2 Assistant Professor and Innovation Chair in Electronic Commerce, Faculty of Law, University of Toronto. 
a system under which no such competition exists? Or in other words, what justifies augmenting the market power of copyright holders beyond the level conferred upon them in a competitive market by virtue of their exclusive rights? Second, do markets for copyrighted works actually fail such that society is better off by shifting from a paradigm of competition to a paradigm of regulated monopolies?

In recent work I have questioned the various justifications (most of which pertain to some form or another of transaction costs) for the paradigmatic form of collective copyright management: performing rights organizations (PROs). In one article, I argued that the case for PROs is not as straightforward as it is assumed to be. I showed that many of the underlying cost efficiencies that are attributed to PROs are usually simply assumed and, in many cases, could be equally achieved under less restrictive arrangements. ${ }^{3}$ In a companion article, I studied the effect of new technologies on the case for collective administration and demonstrated how, by lowering many of the transaction costs that previously purported to justify the practice, new digital technologies further undermine the justification for collective administration. ${ }^{4}$ In his current paper, Professor Robert, while not in total disagreement with my views, maintains nonetheless that the economics of bundling provide the requisite justification for the practice. He also doubt that technological advances would improve the competition landscape in this area and generally foresees a much greater role for collective administration. He comments on the optimal number of collectives and on their operational efficiency. My comment will focus primarily on Professor Robert's bundling justification, and to a lesser extent on the other points and recommendations that he makes. Structurally, I will follow Professor Robert's order of recommendations.

3 A. Katz, "The Potential Demise of Another Natural Monopoly: Rethinking the Collective Administration of Performing Rights" (2005) 1 Journal of Competition Law and Economics 541 ["The Potential Demise I"].

4 A. Katz, "The Potential Demise of another Natural Monopoly: New Technologies and the Administration of Performing Rights" (2006) 2 Journal of Competition Law and Economics 245 ["The Potential Demise II"]. 


\section{B. COLLECTIVES AND BUNDLING}

The essence of Professor Robert's argument is as follows. Notwithstanding other flaws that might be found in the transaction costs rationales for collective management and the even greater feasibility of individual licensing that new technologies allow, collective management remains an efficient mode to administer copyrights because what collectives do is bundle large repertoires of works under a single blanket licence. Such bundles are attractive, according to Robert, because they allow rights holders to extract revenues while limiting the deadweight losses otherwise associated with the pricing of copyrighted works on a per-work basis. ${ }^{5}$ Essentially, bundling allows the seller to price discriminate without needing to know how different consumers value different works. Bundling achieves this result because, under the law of large numbers, consumers' willingness to pay for a bundle tends to average out. Therefore, bundling makes it easier for the seller to predict how consumers will valuate a collection of works, without needing to know how they value any individual work. ${ }^{6}$

I have no quarrel with the argument that bundling of information goods can be efficient (as can other forms of non-linear pricing). I doubt, however, that the economic literature on bundling of information goods can adequately explain, let alone justify, collective administration. While on its face attractive, closer examination reveals that the bundling argument shares the same flaws with many other efficiencybased justifications for collective administration. Like them, the bundling argument simultaneously proves too much and explains too little.

\section{1) Proves Too Much}

The bundling argument proves too much because it fails to notice a subtle, yet critical, distinction between acknowledging that bundling

5 It should be noted that although that is the common practice, collective administration does not necessarily imply blanket licensing of the collective's repertoire. There is nothing that prevents collectives from licensing on a perunit basis, while setting the prices collectively. For convenience however I will proceed on the assumption that whenever a collective exists, a blanket licence covering the collective's entire repertoire will be offered.

6 J. Robert, "An Evaluation of Collective Copyright Management in Canada." See Chapter 5 of this book. 
can be efficient and concluding that bundling everything is efficient. The bundling argument, as presented, is based on a false assumption that only two options are available: management by the individual authors on a per-work basis or management by a collective using a "mega-bundle" - a blanket licence covering all works. But accepting that management by individual authors on a per-work basis may be inefficient only implies that management will be done by different sorts of intermediaries and aggregators; it explains why we have different kinds of publishers, producers, and agents - it does not explain the need for a single managing entity.

In other words, noting that micro-management may be inefficient does not imply that economies of scale, scope, or aggregation ${ }^{7}$ can only be achieved through mega-management by copyright collectives. It may prove the desirability of intermediaries. It may explain why those intermediaries may occasionally sell bundles. But the perceived inefficiency of management at the author/work level does not prove the desirability of a single, ultimate intermediary, offering a mega-bundle. As I have noted previously, the bundling argument fails to distinguish between a situation in which an individual copyright holder (or an individual intermediary) sells bundles on a blanket basis and a situation in which all copyright holders pool their rights and sell only a single bundle. ${ }^{8}$ In the first case, bundles compete with each other, with the likely result of a greater quantity and variety of bundles, offered at different sizes and shapes and sold at lower prices, whereas in the second, only a mega-bundle is offered, presumably at a higher price and lower quantity (and by definition no variety).

The question is then why should we not assume that beyond some point, any bundle is subject to diminishing returns to size and scope, and that given the heterogeneity in consumers' preferences, these sizes and scopes vary substantially across different users of different works. We may also assume that competitive markets are quite capable of providing incentives for efficient bundle formation and pricing. The alleged superiority of the all-encompassing mega-bundle that faces no

7 The term "economies of aggregation" comes from Y. Bakos and E. Brynjolfsson, "Bundling and Competition on the Internet" (2000) 19 Marketing Science 63 ["Bundling and Competition on the Internet"].

"The Potential Demise I," above note 3 at 553-59. 
competition must, on the other hand, assume that the marginal utility from adding an extra work to the bundle never diminishes and always outweighs the inefficiencies caused by lack of competition. It must also assume, under the prevailing regulated-monopoly paradigm, that the regulator - the Copyright Board - can successfully mimic the prices and terms under which competitive bundles would be licensed. Despite the best intentions of the Board, the parties that litigate before it, their lawyers, and their experts, I doubt that we can safely make such an assumption.

In fact, closer reading of the bundling literature reveals the shortcomings of applying it to justify collective administration. Professor Robert relies on Bakos and Brynjolfsson (BB) who demonstrated that the optimal pricing for information goods by a monopolist is a single, all-inclusive bundle. ${ }^{9}$ However, the BB model relies on the following specific assumptions: first, that the marginal cost of adding works to the bundle is zero; second, that consumers' valuations of the works in the bundle are independent and identically distributed (i.i.d.); and third, that consumers do not have budget constraints. These assumptions might not be applicable to the current context, or at least suggest that the model applies less frequently than suggested by Robert. ${ }^{10}$

More importantly, the BB model assumes a monopolist who owns all content and only has to determine whether to sell this content as a bundle or on a per-work basis. The model shows that, when such a monopolist exists, bundling may increase profits while reducing deadweight loss through de facto price discrimination. But the model does not address the question of whether having such a monopoly is desirable in the first place, or whether it is possible and preferable to have several bundlers competing against each other. Nonetheless, in a subsequent paper the same authors analyze the consequence of moving from a marketplace with two rival bundlers, each offering its own large bundle, to a monopolist who offers a mega-bundle. ${ }^{11}$ In that ex-

9 Y. Bakos \& E. Brynjolfsson, "Bundling Information Goods: Pricing, Profits, and Efficiency" (1999) 45 Management Science 1613 ["Bundling Information Goods"].

10 See S. Viswanathan and G. Anandalingam, "Pricing Strategies for Information Goods" (2005) 30 Sadhana 257 (discussing some of the limitations of the BB model).

11 "Bundling and Competition on the Internet," above note 7 at $73-74$. 
tended model they show that since the bundles are not overlapping consumers purchase both of them (while they are not interested in all the works in both bundles, they are sufficiently interested in some of the works in each). In the two-bundler marketplace, the deadweight loss converges to zero, while consumers retain a third of the consumer surplus. However, a merger between the two bundlers allows the resulting monopolist to capture the entire consumer surplus and double its gross profits. ${ }^{12}$ This is undeniably good for the bundlers but comes directly at the expense of consumers.

This situation is analogous to the question of copyright collectives. Consider the paradigmatic case of performing rights. Over 80 percent of all popular music is controlled by the four big multinational labels. ${ }^{13}$ Each of them may offer its own large bundle in the form of a blanket licence. Thus, users who are interested in access to very large repertoires may purchase all such bundles. Deadweight loss may be minimized while consumers retain part of the consumer surplus. As the number of bundles increases, the value of any particular bundle decreases, which reduces each bundlers' market power and corresponding prices. If, however, there is only a single bundler (i.e., a copyright collective), this competition disappears and the collective can capture the entire consumer surplus at the expense of consumers, without any marked improvement in efficiency. In sum, instead of providing a novel efficiency-justification for collective administration, the bundling literature actually highlights another ground for objection.

Moreover, even if under some conditions the "economics of aggregation" may confer competitive advantage on one bundler who is then able to out-compete any other competitor (thus in essence creating a new type of natural monopoly), ${ }^{14}$ there is a critical difference between such a situation and collective administration. While in both cases all works are ultimately provided as part of a single bundle, in the first case market competition determines the identity of the successful bundler, and the threat of being overtaken by another bundler through periodical competition-for-the-field disciplines its behaviour

12 Ibid.

13 See "The Potential Demise I," above note 3 at 575.

14 See "Bundling and Competition on the Internet," above note 7 at 68-70 (showing that when bundlers compete for content on exclusive basis, a larger bundler may out-compete smaller ones). 
(at least as long as creators are free to license through other bundlers as well). ${ }^{15}$ In the case of collective administration, however, at least in its current form in Canada, no such competitive discipline exists. This is because in some cases the collective model is dictated by the law, while in others the monopolistic position of the collective is cemented with exclusive relations between the collective and the copyright holders that it represents. ${ }^{16}$

Lastly, Robert's examples of bundles actually weaken the case for collective administration, instead of supporting it. Indeed, bundling information goods is ubiquitous, with various bundles often competing with each other. Newspapers are bundles because every issue contains various sections and articles and readers may have different valuations for different articles. But newspapers compete with each other (as well as with other products or services), and absent evidence to the contrary, we have no reason to believe that bundling them all together provides any social value. A more reasonable assumption would be that the benefits of competition among newspapers dwarfs any marginal value created by a super-newspaper. Even JSTOR, the electronic archive for scholarly journals mentioned as an example of a mega-bundle, is markedly distinct from the collective model. JSTOR is a non-profit organization, serving academic and other scholarly institutions. It could be seen, in the words of Bakos and Brynjolfsson as "a consortium or club of consumers [that] purchase access to a variety of information goods and make them available to all members for a fixed fee. ${ }^{17}$ Although it is licensed by publishers, it is not owned or governed by them; nor is it run for their benefit. ${ }^{18}$ JSTOR has a "dual mission to create and maintain a trusted archive of important scholarly journals,

15 If this requirement is met, the scenario described by Bakos and Brynjolfsson may not materialize.

16 See "The Potential Demise I," above note 3 at 578-82 (discussing the contestability of PROs), and "The Potential Demise II," above note 4 at 264-73 (discussing the Canadian model).

17 "Bundling Information Goods," above note 9 at 1625.

18 Under s. 2 of the Copyright Act, R.S.C. 1985, c. C-42, a "collective society" is defined as

a society, association or corporation that carries on the business of collective administration of copyright or of the remuneration right conferred by section 19 or 81 for the benefit of those who, by assignment, grant of 
and to provide access to these journals as widely as possible." ${ }^{19}$ Its collection is no doubt impressive, but does not cover all scholarly journals. In particular, consistent with its archival mission, its "moving wall" policy excludes the more recent issues of participating journals. Thus cutting-edge scholarship (where competition between articles and journals is presumably fiercer) is licensed by publishers directly, or through other intermediaries. Moreover, as it is only a non-exclusive licensee, JSTOR is just one among many other gateways to the works available through its collection.

In sum, the economics of bundling sheds very faint positive light on the question of collective copyright management. The ability to bundle can explain the existence of publishers and other forms of market intermediaries, but the economics of bundling does not teach us that the most efficient bundle is the mega-bundle, offered by a copyright collective. What the economics of bundling can teach us when applied to copyright collectives is that once a model of collective management is chosen (for whatever reason) the fact that the collective issues a blanket licence is not in itself necessarily objectionable. But that is all. Beyond that, the bundling argument simply proves too much.

\section{2) Explains Too Little}

In addition to proving too much, the bundling argument, as presented, explains too little by failing to take into account how collective administration is actually practised in Canada (and elsewhere). A closer look reveals that the argument does not attempt to explain realities that are inconsistent with the argument but are nonetheless pervasive. I will

licence, appointment of it as their agent or otherwise, authorize it to act on their behalf in relation to that collective administration, and

(a) operates a licensing scheme, applicable in relation to a repertoire of works, performer's performances, sound recordings or communication signals of more than one author, performer, sound recording maker or broadcaster, pursuant to which the society, association or corporation sets out classes of uses that it agrees to authorize under this Act, and the royalties and terms and conditions on which it agrees to authorize those classes of uses, or

(b) carries on the business of collecting and distributing royalties or levies payable pursuant to this Act. 
demonstrate this point through the recent decision of the Copyright Board, approving the tariff proposed by CMRRA/SODRAC for online music services. ${ }^{20}$

Online music services, such as Apple's iTunes, allow their customers to purchase and download songs. These songs are reproductions of sound recordings as well as of the underlying musical and often literary works. When the record labels producing these songs sell them as CDs they have acquired from the copyright holders all the necessary rights to reproduce works and create the copies. But when the same songs are sold online as digital files, further reproduction of the works is done by the online sellers, who authorize their customers to download the files and often to make some copies thereof. Technically, these reproductions and authorizations require a licence as well. In the US, record labels generally secure all the necessary rights and provide them to online services for one fee. ${ }^{21}$ In Canada, however, record labels can only grant online services the right to reproduce the sound recording, but the right to reproduce the musical work must be licensed separately and can be obtained from two copyright collectives, CMRRA and SODRAC through their jointly owned corporation CSI. But that is not enough, because the Copyright Board had previously held that the online distribution of the songs also constitutes "communication to the public by telecommunication," which is a separate right requiring a separate licence. ${ }^{22}$ In Canada, such a licence can only be secured from a collective, yet a different collective: SOCAN. ${ }^{23}$ But if

20 Statement of Royalties to be Collected by CMRRA/SODRAC Inc. for the Reproduction of Musical Works, in Canada, by Music Services in 2005, 2006 and 2007 (2007), 55 C.P.R. (4th) 89 (Copyright Bd.).

21 Ibid. at para. 58 (testimony of Mr. Effy Cue, Vice-President of Apple's iTunes).

22 Statement of Royalties to Be Collected by SOCAN for the Communication to the Public by Telecommunication, in Canada, of Musical or Dramatico-Musical Works (2006), 52 C.P.R. (4th) 375 (Copyright Bd.), aff'd Canadian Wireless Telecommunications Association v. Society of Composers, Authors and Music Publishers of Canada, 2008 FCA 6.

23 A tariff covering these rights has been recently approved by the Copyright Board, see Statement of Royalties to Be Collected by SOCAN for the Communication to the Public by Telecommunication, in Canada, of Musical or Dramatico-Musical Works, [2007] C.B.D. No. 7 [Tariff No. 22.A (Internet - Online Music Services) 1996-2006], online: www.cb-cda.gc.ca/decisions/i16032007-b. pdf. 
online distribution of songs is indeed "communication to the public by telecommunication," then under section 19 of the Copyright Act online sellers are liable to pay an additional fee, "equitable remuneration," to the NRCC, ${ }^{24}$ another collective, which will divide such royalties between the performers of the recorded songs and the producers of the sound recordings - the same record labels with which the online sellers have already negotiated. ${ }^{25}$

The bundling argument may explain why record labels might find it beneficial to bundle works and offer their respective repertoires on a blanket basis, and it may also explain why online music services might want to offer bundles to their customers, but it contributes very little to our understanding of the structure of the online music market in Canada. First, the bundling argument does not explain why in the US all the rights that are necessary to run a business such as iTunes can be secured and provided by the producer - the record label - while in Canada some rights may be licensed by the label in a free-market environment whereas others can only be secured from two (or perhaps three) separate regulated collectives. Second, it does not explain why excluding certain rights from what seems like a functioning market is advantageous, not only from the collectives' (and perhaps their members') perspective but also from a general welfare point of view. Third, it raises the question why, despite the claimed efficiencies of the mega-bundle, at least in the case of music downloads and at least so far, the business model that seems to be more successful is iTunes' pertrack model and not some of its competitors' one-fee-unlimited-access model. ${ }^{26}$ In fact, a possible explanation is that whereas the bundling literature has focused on how bundling maximizes sellers' profits, competition between online music services forces them to design their services in a manner that maximizes consumers' welfare.

Lastly, according to Professor Robert one of the advantages of collective administration is that collectives allow access to every work in their repertoire, thus avoiding the deadweight loss caused when copyrighted works are sold separately. But the online music example reveals

24 The Neighbouring Rights Collective of Canada.

25 So far, no such tariff has been proposed to the Copyright Board.

26 See for example, Napster to Go, online: http://napster.ca/more_about_napster_ ntg.html. 
that this benefit of the mega-bundle must be exaggerated. While the blanket licence issued by a collective generally does cover all the work in the collective's repertoire, under current practices the distribution of copies is typically separate from the licensing of various uses authorized by collectives. Thus, whatever access benefits the mega-bundle confers upon the user are limited to the copies that she actually bought. The inevitable inefficiencies resulting from the grant of intellectual property rights are not fully solved by the bundles currently offered by copyright collectives. The library is bound to the collection of books that it bought; the discotheque to its collection of CDs. Even if they get a licence from Access Copyright or SOCAN, entitling them to photocopy every work or play every song, they can only photocopy or play works that they actually bought, separately. For these reasons, the bundling argument explains too little.

\section{NOTE ON INCENTIVES}

Professor Robert finds the collective model attractive because in his view it allows maximizing rewards to creators without impeding access. But as noted before, licensing under competitive conditions does not prevent the realization of whatever economies of scale, scope, or aggregation that might exist and therefore would be (at least) just as good. Nonetheless, one may argue (and I think Professor Robert implies this argument) that collective management is still superior because maximizing the reward to creators increases the incentives to create, thus furthering the aims of copyright law. My response is twofold. First, if accepted, such an argument will have much wider consequences because it does not stop at collective administration. Essentially it will permit any kind of collusion between IP owners because allowing IP holders to collude when they find it worthwhile necessarily increases their profit, thereby increasing the ex ante expected return on the investment and the incentive to invest. In the same vein, a right to collude may decrease the risk of competition from non-infringing works or technologies, which again may increase the expected return and incentive to invest. But this is definitely not the law. Collusion between IP holders is illegal and the competition laws do not make any dynamic efficiency defense of this kind available to IP holders - nor should they. Maximizing reward has never been the aim 
of intellectual property law, and overcompensating creators may itself be distortionary. ${ }^{27}$ Second, even if increasing reward equals increasing the incentives to create, it does not necessarily mean that it increases the incentives to create socially valuable works. In fact, it may well create incentives to create more works, but mediocre ones.

While copyright law allows the copyright owner to exclude others, this right does not guarantee any reward. Reward in a market where works compete with each other will only be available if two conditions are met. First, the work must be valuable to users (otherwise they will not pay), and second, the work must offer something unique relative to other works that makes it preferable to those existing works. If the work is nothing but a mere or very close substitute to other works, competition between such works will drive their price towards marginal cost (i.e., towards zero). Moreover, the value derived from every work may be comprised of a generic value of playing $a$ song, and the unique value of playing the song: the marginal value of the particular song. Under competition, an individual creator cannot capture the entire value of the work, only the marginal value of his work relative to other imperfectly fungible works. Assume there are three types of works: masterpieces, generic, and bad. Under competition the bad will not be rewarded (nobody buys them) and the generic will face fierce competition from other generic works providing the same value and therefore will get zero or very little at best. Only the masterpieces will be rewarded but will get only a reward reflecting their marginal value. This creates an incentive to create works of higher quality or variety because only those will be rewarded.

Under collective administration the incentives may be different. The collective's all-or-nothing policy allows it to capture the entire surplus from users - for example the value of all music, not only the sum of the marginal values of works in its repertoire. The pie available for distribution is larger than before. Now I assume that the collective distributes the monies collected according to the number of uses by users, not on a merit basis. I further assume that users such as radio stations require a variety of songs and therefore may be expected to play some generic songs, not only masterpieces. These two assump-

27 See for example, Mark A. Lemley, "Property, Intellectual Property, and Free Riding" (2005) 83 Tex. L. Rev. 1031 at 1058. 
tions imply that even the randomly selected generic work will get a share of the monopolistic pie, which is bigger than zero. Therefore, from an ex ante perspective, while under competition, the expected return from creating a mediocre, generic work is zero, the expected return for the same work in a collective setting is greater than zero. Therefore, under collective administration, even works whose creation has added no social value get rewarded. This may entail a higher incentive to create, but higher incentive to create mediocre works.

This is of course not the only possible outcome. It is possible that the elimination of price competition among creators will lead them to compete on non-price dimensions. Such competition may be on quality (which may be a good thing, but not necessarily so, i.e., merely bells and whistles), but it may also encourage indirect price competition in the form of payola. ${ }^{28}$ While anticipating the exact type of impact generated by the additional rents available through collective administration is beyond the scope of this comment, the general point is that we have no guarantee that the additional rents will necessarily create the desirable type of incentives.

\section{THE NUMBER OF COLLECTIVES}

To the questions of whether the number of collectives operating in Canada is too large, and whether there is a role for mandating the creation of a "super-collective," Professor Robert answers in the negative. He maintains that no apparent obstacles exist preventing the efficient amalgamation or disintegration of existing structures, should it become efficient to do so. I agree that the number of collectives does not necessarily imply any inefficiency and that creating a supercollective is not a priori beneficial, but I think that a more nuanced analysis is required here. Regardless of whether a collective model of rights management is desirable or not, once such a model exists the number of collectives that a user has to deal with can matter. Note that the question is not how many collectives exist generally, but how many collectives have to be dealt with to allow a single activity. When a single economic activity implicates more than one type of right and

28 See R.H. Coase, "Payola in Radio and Television Broadcasting" (1979) 22 J.L. \& Econ. 269; "The Potential Demise I," above note 3 at 582-90. 
each type is administered by a separate collective, the multiplicity of licences required can lead to inefficiency. This can happen, for example, in the case of broadcasts when, as the Copyright Board noted, "[a] sound recording cannot be communicated [to the public] without communicating the underlying work and performances at the same time."29 This inefficiency stems from the problems of double marginalization, existing whenever complementary inputs are each sold by a separate monopolist. Each monopolist, attempting to increase its profit, sets a monopoly price while ignoring the fact that her higher price negatively affects the demand for the complementary good. The result is that the total price the user has to pay for all complements is too high, leading to underuse or, in the extreme case, to non-use of the resource. The phenomenon has been recently coined "the tragedy of the anticommons," ${ }^{30}$ or the problem of "fragmented management." ${ }^{31}$

Thus, the fact that users often have to deal with only a small number of monopolist-collectives with regard to the same use does not imply that the inefficiency described above does not exist or that it is insignificant. It may - and probably does - exist whenever overlapping licences must be secured from separate collectives. Arguably, the problem has been partially addressed by Parliament when it enacted section 19 of the Copyright Act, which provides that payments for public performance of sound recordings will be made in a single payment, later divided between the makers of the sound recording and the performing artists. The problem has been further addressed by the Copyright Board, which has adopted a policy of consolidating tariff hearings when these deal with overlapping rights. ${ }^{32}$ It seems to me that

29 Re NRCC Tariff 1.C (CBC-Radio), 1998 to 2002 (2000), 9 C.P.R. (4th) 504 (Copyright Bd.) [Re NRCC Tariff 1.c].

30 M.A. Heller, "The Tragedy of the Anticommons: Property in the Transition from Marx to Markets” (1998) 111 Harv. L. Rev. 621.

31 D.J. Gervais and A. Maurushat, "Fragmented Copyright, Fragmented Management: Proposals to Defrag Copyright Management" (2003) 2 C.J.L.T. 15.

32 See Re NRCC Tariff 1.c, above note 29; see also "Bill C-32 - Ten Years Later," Speech given by the Honourable Justice William J. Vancise Chairman of the Copyright Board of Canada (Seminar jointly sponsored by the Intellectual Property Institute of Canada and McGill University, Toronto, 23 August 2006), online: www.webcitation.org/5OskIM9RR. According to Justice Vancise, though, the policy does not provide a perfect solution. It is not clear whether it can prevent all attempts of individual collectives to act strategically. 
more thought should be given to whether a more systematic solution is required.

Given that the fragmentation of licences required for single activities among several monopolist-collectives generates inefficiencies, from which copyright owners as a whole also suffer, one may wonder what prevents the collectives themselves from integrating, either completely or only with regard to their licensing activities. While this is a question worth exploring, Professor Robert's discussion of the productive inefficiencies that characterize many Canadian collectives may suggest that collectives do not face the best set of incentives for improving their own efficiency, as discussed below.

\section{E. COLLECTIVES' PRODUCTIVE INEFFICIENCIES}

Professor Robert raises some concerns about Canadian collectives' productive inefficiencies. He notes that they are slow in adopting new technologies that could streamline their operations and probably distribute too little from what they collect.

I believe that these problems are more systemic and it is not simply a matter of time until productive efficiency will make inroads into Canadian collectives' operations. In fact, the inefficiencies that Professor Robert describes reflect an inherently poor governance structure. While he mentions that collectives rarely face competition and its attendant market discipline, Professor Robert believes that, as member-owned organizations, collectives do face incentives assuring their efficiency because the member-owners are those who benefit from greater efficiency and pay the price for its absence. I think that this belief is naïve. In fact, in many cases copyright collectives may demonstrate some of the worst forms of corporate governance. If copyright owners are indeed numerous and dispersed, then we may assume that Canadian collectives will exhibit the classic problems associated with the separation of ownership and control. Collective action problems would prevent the individual members from exercising their right of control to the benefit of insiders (either members with greater representation or influence or managers). While such problems associated with dispersed ownership are pervasive in the corporate world (and have generated a voluminous corporate governance literature), the Canadian collectives' situation is quite unique among Canadian 
corporations because not only do they not face market discipline, they also do not have to respond to other disciplinary threats: the threat of exit by their members, or the threat of takeover.

Under such conditions, productive inefficiency seems almost inevitable. Whether or not the government can or should do anything about it is another question, but at least this provides yet another reason to prefer a competitive structure when possible, or at least abolish restrictive membership terms (such as SOCAN's requirement that members fully assign their rights to the organization), which unnecessarily constrain the limited ability of members to exit. ${ }^{33}$

\section{F. INFORMATION TECHNOLOGIES: CHALLENGES AND OPPORTUNITIES}

Professor Robert raises several objections to my argument that advancements in information technology can render collective administration (even more) unnecessary. He maintains that the use of Digital Right Management (DRM) technologies is not desirable because: (i) it is costly and reduces consumers' welfare; (ii) it raises serious privacy issues; and (iii) it is inefficient because, as the bundling argument implies, per-work licensing is inefficient.

While I am far from being a proponent of DRM technologies and have no stake in their success, as far as I know the government has not seriously considered any proposal to outlaw them. ${ }^{34}$ Therefore, I take it as a given that such technologies exist, that they will be further developed and occasionally implemented. And like any technology, it may be used for more or less beneficial purposes, and at times abused. My comment will proceed on these assumptions.

It seems to me that arguing that DRM technologies unambiguously reduce consumers' welfare is a problematic proposition. In theory, they may reduce some consumers' welfare (e.g., a person who buys a copy and wishes to make copies for his friends, or for backup purposes, or for copying extracts for a classroom presentation), but at the same

33 See "The Potential Demise I," above note 3 at 578-82 (discussing the limited contestability of performing-rights organizations).

34 This is of course an understatement. The only realistic policy discussions apply to the scope of legal protection that will be afforded to such technologies. 
time increase other consumers' welfare (e.g., enable restricted access at lower prices for users who otherwise would not be willing to pay the price for a copy with broader privileges). In the absence of restraints on competition, I would think that the market could determine the menus of option available to consumers and price them accordingly, and that the law may occasionally have to intervene when this assumption turns out to be untrue..$^{35}$ The simple point is that we cannot make a priori general cost-benefit analyses of such technologies.

Privacy concerns are essentially a subset of the previous point. Consumers may vary in their price-adjusted preferences towards privacy and we can assume that the market can respond according to such preferences (while acknowledging that some market imperfections, such as information asymmetry, or perhaps behavioural biases, may justify occasional intervention). But more importantly, I am afraid that the privacy issue and the question "To what extent are we willing to allow corporations to monitor our private use of musical work(s)?"36 are a red herring. For the most part, collectives administer rights that are relevant to commercial users, not to individuals.

Moreover, since DRM and other technologies may be highly relevant to the mandate of collectives (either because they may prevent non-licensed uses, facilitate more finely tuned pricing schemes, and improve monitoring to assist in the major challenge of fairly dividing the collected royalties), Robert's implied suggestion that extended collective management will spare us the ills of DRM is false. As I have previously noted, collectives, too, may implement these technologies, in a way that will only increase the concerns about DRM. ${ }^{37}$

35 France has recently established a Regulatory Authority for Technical Measures, whose mandate is to assure that DRM systems do not prevent interoperability and do not prevent users from benefiting from exceptions available to them under the copyright law; see N. Jondet, "DRM Watchdog Established in France," French-Law.net (11 April 2007), online: www.webcitation. org/5PAylQJkN.

36 Jacques Robert, "An Evaluation of Collective Copyright Management in Canada," chapter 5 of this book at 439 .

37 "The Potential Demise II," above note 4 at 277-79. In fact, collectives may even have stronger motivation than individual rights holders to monitor use because collectives face the challenge of how to distribute the royalties they collect. An individual licensor can grant access to all the works in his repertoire on a blanket basis without worrying much about distribution. 
Lastly, since I have already commented extensively on the bundling argument, I will only repeat the point that if it is efficient to bundle, we may expect that in competitive markets copyright owners, either alone or through intermediaries, will offer bundles of varying sizes and shapes. Nothing prevents them from doing so. In fact, casual observation of the online music markets reveals that two models are currently available: a per-song model $\grave{a} l a$ iTunes, and a subscriptionbased unlimited-access model à la (the new) Napster. While industry experts and executives argue which model is preferable (currently the per-song model has the upper hand), Professor Robert seems to be so confident that an even more expansive bundling model is preferable that he would like to have it extended. I am less ambitious and make no predictions. If it were up to me I would only make sure that market conditions remain such that industry executives can experiment with different models and let us, consumers, choose at any time the option that suits us best.

\section{G. EXTENDING THE USE OF PRIVATE COPYING LEVIES}

Professor Robert lastly recommends extending the use of private copy levies to address the problems created by other advances in information technologies, such as peer-to-peer networks. He correctly maintains that new technologies enable new forms of copying and that outlawing such activities when enforcement is too costly (or intrusive, I would add) is not a good policy prescription. He therefore suggests that the law should clarify and exempt some types of copying, while imposing levies, administered by collectives, to compensate rights holders. While this is a topic that deserves its own symposium, I will only make two short comments.

I agree with Professor Robert that prohibition rules that cannot be enforced do not make good policy. But the alternative to prohibition is not necessarily taxation (which is what private copying levies essentially are). Exemption is also a solution. In fact, copyright's traditional response to prohibitively high costs of maintaining a system of exclusive rights has been exempting such uses. ${ }^{38}$ While I would not

38 W.J. Gordon, "Fair-use as Market Failure - A Structural and Economic-analysis of the Betamax Case and Its Predecessors" (1982) 82 Colum. L. Rev. 1600. 
rule out the possibility of using levies to address the problems arising out of peer-to-peer technologies and other forms of copying, a system of levies does not come without its own flaws, inefficiencies, and distortions. Therefore, before adopting and extending such solutions, I would first like to be convinced that these types of copying are indeed problematic, in the sense that they cause real harm translated into real diminishment of the incentives to create, ${ }^{39}$ that levies can actually address this problem, and that the costs associated with such system are smaller than the benefits it creates. I doubt whether the current private copying regime passes this test and would like to know more before I would recommend extending it.

\section{H. CONCLUSION}

Professor Robert's main conclusion is that "a system of collective management is justified in order to market blanket licences for extended repertoires." ${ }^{40}$ He so concludes on the basis of the perceived efficiencies of the mega-bundle, the blanket licence typically issued by copyright collectives. But the efficiencies of large scale bundling can only explain why micro-management by individual authors on a per-work basis may not always be efficient, and why intermediaries may create bundles. The theory falls short of explaining why the benefits of bundling necessarily imply the formation of the ultimate mega-bundle. Therefore, the bundling argument shares the same flaws of all other

39 The few empirical studies attempting to evaluate the impact of file sharing on sales of music have reached inconsistent conclusions. While S. Leibowitz, "File-sharing: Creative Destruction or Just Plain Destruction?" (2006) 49 J.L. \& Econ. 1 at 24 finds a close link between changes in record sales and changes in file sharing, F. Oberholzer and K. Strumpf, "The Effect of File Sharing on Record Sales: An Empirical Analysis" (2007) 115 Journal of Political Economy 1 at 38-40 conclude that downloading has no significant impact on album sales. In the case of DVDs, M.D. Smith and R. Telang, "Piracy or Promotion? The Impact of Broadband Internet Penetration on DVD Sales" (June 2006), online: http://ssrn.com/abstract=918240, find that increased broadband Internet penetration leads to a significant increase in DVD sales. Even if file sharing has harmed the recording and film industries, the translation of such harms to reduced incentives to create is even less clear.

40 Jacques Robert, above note 36 at 441. 
efficiency-based justifications for collective administration: they all explain the need of intermediaries, but not the need for a single one.

Canada's existing system of copyright collectives has grown out of legislative reforms based on the government's view that "[i]n many cases, it is impractical, if not impossible, for negotiations and transactions involving copyright to occur without the presence of an organized 'society' representing the interests of creators and copyright owners." ${ }^{41}$ It was also believed that legislative reform was necessary because new collectives could not be formed because of concern with prosecution under Canada's competition laws. ${ }^{42}$ This rationale for collective administration no longer holds. Therefore, to the extent that these reforms indeed made collective administration immune from Canada's competition laws, my only recommendation is to repeal this wholesale immunity. Collective administration of copyright should not be treated differently from any other horizontal arrangement between competitors. It should be allowed when its efficiencies outweigh its costs and outlawed when they do not. More often than not they do not.

41 J. Erola and F. Fox, From Gutenberg to Telidon: A Guide to Canada's Copyright Revision Proposals (Ottawa: Government of Canada, Consumer and Corporate Affairs Canada, 1984) at 6. 